\title{
Kinematik PPP-AR ve Geleneksel PPP Yöntemlerin Performanslarının Değerlendirilmesi: Antarktika Yarımadası Örneği
}

\author{
Mert Bezcioğlu ${ }^{1}$, Cemal Özer Yiğit ${ }^{1,2}$, Mehmet Nuri Bodur ${ }^{3}$ \\ ${ }^{1}$ Gebze Teknik Üniversitesi, Mühendislik Fakültesi, Harita Mühendisliği Bölümü, Kocaeli. \\ ${ }^{2}$ School of Earth and Planetary Sciences, Curtin University, Perth, WA, Australia. \\ ${ }^{3}$ Hakkâri Üniversitesi, Mühendislik Fakültesi, Inşaat Mühendisliği Bölümü, Hakkari \\ e-posta:mbezcioglu@gtu.edu.tr
}

Geliş Tarihi: 04.10.2018 Kabul Tarihi: 06.02.2019

Öz

Anahtar kelimeler PPP-AR, Geleneksel PPP, GNSS, Kinematik Konum Belirleme,

Antarktika
PPP (Precise Point Positioning-Hassas Nokta Konumlama) yöntemi ile hem statik hem de kinematik modda tek GNSS (Global Navigation Satellite Systems) alıcısı ile bağıl (rölatif) konum belirleme yöntemine oldukça yakın bir seviyede konum bilgisi elde edilebilmektedir. Bu yöntem hem maliyet hem de oldukça kolay uygulanması sebebi ile beklenen doğruluk ve hassasiyeti karşılaması durumunda bağıl konum belirleme yöntemine bir alternatif olarak kullanılmaya başlanmıştır. Bu çalışmada, Antarktika Yarımadasında bulunan Livingston Island' da bir Zodyak botu ile iki farklı günde bir dizi GNSS ölmeleri yapılmış ve GNSS verileri; bağıl yöntem, PPP-AR (Ambiguity Resolution) ve Geleneksel PPP yöntemleriyle ayrı ayrı değerlendirilmiştir. PPP-AR ve Geleneksel PPP yöntemlerinin kinematik konum belirleme performansı bağıl yöntemle karşılaştırılmıştır. Sonuçlar PPP-AR yönteminin üstünlüğünü açıkça göstermektedir.

\section{Evaluating Performance of Kinematic PPP-AR and Traditional PPP Methods: Antarctic Peninsula Case}

\begin{abstract}
Positioning information using PPP (Precise Posint Positioning) method can be obtained with a single GNSS (Global Navigationing Satellite Systems) receiver in both static and kinematic mode at a level very similar to the Relative Positioning method. This method has been used as an alternative to the relative method in recent years since it provides both cost and ease of application and also provides the expected accuracy and sensitivity for location information. In this study, on Livingston Island, which is located in the Antarctic Peninsula, has been made a series of GNSS measurements on two different days with a Zodiac boat. GNSS data were evaluated separately by the relative method, PPP-AR (Ambiguity Resolution) and Traditional PPP methods. Kinematic positioning performance of PPP-AR and Traditional PPP method were compared with the relative method. The results clearly demonstrate the superiority of the PPP-AR method.
\end{abstract}

(c) Afyon Kocatepe Üniversitesi

\section{Giriş}

Son yıllarda gelişen teknoloji ve algoritmalar sayesinde GNSS-PPP yöntemi oldukça farklı mühendislik uygulamalarında kullanılmaktadır. Bu yöntemin en önemli avantajı, bir referans (baz) istasyon veya istasyonlarından herhangi bir ek veriye ihtiyaç duymadan konum bilgisini kullanıcıya sağlayabilmesidir. Fakat yöntemin hassas koordinat bilgisi üretebilmesi için, IGS ya da GNSS araştırma merkezleri gibi benzeri kuruluşların sağladığı, hassas uydu yörünge ve saat bilgilerinin bilinmesi gerekmektedir. PPP'nin sadece tek bir GNSS alıcISI bilgilerine ihtiyaç duyması da saha işletim maliyetlerini azaltmaktadır. $1 \mathrm{~Hz}$ ve daha yüksek frekanslı GNSS verisi ve Kinematik PPP yönteminin kullanıldığı alanlar arasında yapı sağlığı takibi, deprem erken uyarı, sismojeodezi ve heyelanların 
izlenmesi gibi alanlar bulunmaktadır (Yigit 2016, Larson et al. 2003, Kouba 2003, Xu et al. 2013). PPP Yönteminin kullanıldığı kıyı ve denizle ilgili çalışmalar ise hidrografi ölçmeleri, tsunami erken uyarı sistemleri, gemiler, şamandıralar ve yüzen platformlar, deniz jeodezisi, oşinografi, kıyısal deformasyon gözlemleri olarak karşımıza çıkmaktadır (Bisnath and Gao 2009).

GNSS sistemlerinin gemiler, yüzen platformlar ve hava araçları gibi alanlarda kullanımı kinematik yöntem ile doğrudan ilişkilidir. Kinematik yöntemden elde edilen koordinatların duyarlılığı oşinografi, gelgit değişimleri, deniz tabanı jeofiziği ve erken uyarı sistemlerinin kurulması gibi uygulamalar için son derece önemlidir (Geng et al. 2010). Uydularla Konum Belirleme Sistemlerinin Kinematik modda ulaştığı doğruluk günümüzde $\mathrm{dm} / \mathrm{cm}$ seviyesine ulaşmasıyla beraber kinematik GNSS yöntemin deniz, göl, baraj vb. alanlarda kullanımı ve bununla beraber bu alanda yapılan çalışmalar artmış bulunmaktadır. Örneğin, GPS sistemlerinin gemilere monte edilen akustik aletlerle kombinasyonu sonucu deniz tabanı kabuk deformasyonunu tespit edilebilmektedir (Chadwell and Spiess 2008). Diğer bir çalışma alanı olarak GPS mareograf (buoy) sistemlerinin uydu altimetre kombinasyonları sayesinde ortalama deniz seviyesinin belirlenmesi ve tsunami gözlemleri yapılabilmektedir (Kato et al. 2005, Watson 2005). Bahsedilen deniz uygulamalarının çoğunda, bağıl GPS konumlandırma teknikleri kullanmaktadır. Bu çalışmalara ek olarak Kinematik PPP yönteminin kullanıldığı bir dizi çalışmalar da mevcuttur. Örneğin, Geng vd. (2010), uzak deniz platformlarda kinematik PPP yönteminin performansını araştırmış, bu çalışmada $1 \mathrm{~Hz}$ örnekleme aralığında veri toplamış ve yöntemin performansının uzun süreli gözlemler olması durumunda daha başarılı olduğunu göstermiştir. Marreiros (2012), $1 \mathrm{~Hz}$ veri toplayan bir GNSS alıcısı ile deniz yüzeyi yüksekliği elde etmiş ve elde edilen verilerin uydu altimetre yöntemiyle elde edilen değerler ile uyumlu olduğunu göstermiştir. Alkan ve Öcalan (2013), $1 \mathrm{~Hz}$ veri toplayama kabiliyetine sahip jeodezik ve OEM alıcıları ile Haliç Köprüsü'nde Kinematik PPP yönteminin performansını incelemek için bir tekne ile deney gerçekleştirmiş elde edilen sonuçlar rölatif yöntemden elde edilen sonuçlar ile karşılaştırılmıştır. Son olarak Alkan vd. (2017), sınırlı uydu görüşü olması durumunda kinematik PPP yönteminin performansını ve GLONASS uydularının çözümlere olan katsını incelemiş elde edilen bulgular özellikle uydu görüşünün kısıtlı olduğu durumlarda GLONASS uydularının katkısını açıkça göstermiştir.

Yukarıda bahsedilen çalışmalarda, kinematik PPP çözümleri geleneksel PPP algoritmasını kullanan yazılımlarla gerçekleştirilmiştir. $\mathrm{Bu}$ çalışma kapsamında, yukarıda belirtilen çalışmalardan farklı olarak Antarktika Yarımadasında hem açık okyanusta hem de çevresi buzullarla (Pimpirev Glacier) kaplı olan bir alanda iki farklı günde $1 \mathrm{~Hz}$ aralıklarla GNSS verileri toplanmıştır. GNSS verileri hem PPP-AR hem de Geleneksel PPP yöntemiyle değerlendirilerek yöntemlerin konum belirleme performansı bağıl GNSS çözümleri referans alınarak incelenmiştir. Test ölçmeleri, verilerin değerlendirilmesi ve elde edilen bulgular ilerleyen bölümlerde detaylı olarak açıklanmıştır.

\section{Materyal ve Metot}

Günümüzde GNSS verileri toplandıktan sonra PPP yöntemiyle işlenmesini sağlayan internet tabanlı birçok servis bulunmaktadır. Bu servisler arasında CSRS-PPP, GAPS, Magic-GNSS ve APSS en önemlileri olarak göze çarpmaktadır. Web tabanlı bu servisleri kullanmak için kullanıcın GNSS ölçüleri sonrası elde ettiği RINEX gözlem dosyalarını servise yüklemesi yeterlidir.

NRCan tarafından geliştirilen CSRS-PPP servisi günümüzde yapılan çalışmalarda oldukça sık kullanılmaktadır. CSRS-PPP dünyanın herhangi bir yerinde ve gününde statik ve/veya kinematik çözüme GPS ve GPS/GLONASS uyduların kombinasyonları ile ITRF ve NAD83 referansına göre koordinat bilgisi üretebilen bir sistemdir. CSRS-PPP servisi $1 \mathrm{~Hz}$ ve daha yüksek frekanslı çözüme olanak sağlar ve çözümde RINEX dosyasındaki en son toplanan epok zamanı ve dosyanın sisteme yüklenme zamanına bağıı olarak ulaşılabilen en iyi 
uydu yörünge ve saat ürünlerini kullanmaktadır. Bu servis, ölçü gerçekleştirildikten 1.5 saat sonra çözüm gerçekleştirmeye olanak sağlamaktadır. Ayrıca faz kesikliği filtrelemesi (cycle-slip filtering), uydu ve alıcı anteni faz merkezi kayıklığının giderilmesi (applying satellite and receiver antenna phase centres offsets), referans datum dönüşümü (a reference frame transformation) ve okyanus yüklemesi etkisinin giderilmesi (applying an ocean loading correction) gibi düzeltmeleri de içermektedir (El-Mowafy 2011, Mireault et al. 2008). 16 Ağustos 2018 tarihinde ise, CSRS-PPP servisi kendi içinde bir modernizasyon gerçekleştirmiştir. Geleneksel PPP algoritmasından, yani faz başlangıç belirsizliğinin tam sayı değil kesirli bir sayı olarak kestirilmesinden, PPP-AR algoritmasına, yani faz başlangıç belirsizliğinin tam sayı olarak kestirilmesine geçiş yapmıştır. Bu modernizasyona göre, 4-5 mm arasında yükseklik kayıklık düzeltmesi (height bias correction), kod ve faz ölçüleri için geliştirilmiş tek frekanslı konum bilgisi elde etme (Improved single frequency positioning (code \& phase) solution) sağlanmıştır. Bununla birlikte RINEX v3 veri formatı desteklenmiş ve en önemlisi PPP-AR ve çoklu GNSS uydu çözümleri eklenmiştir (Int Kyn 1). PPP-AR yönteminin en önemli avantajı konum belirme için gerekli hassasiyeti sağlamak için ölçü süresinin uzatılmasına gerek duyulmamasıdır. Ayrıca literatürde yapılan çalışmalar incelendiğinde, PPPAR algoritmasına yeni yaklaşımlar getirilmiştir. Li vd. (2017), L1 ve L2 ham gözlemlerini kullanarak ve eğik (slant) iyonosferik gecikme bileşenini bilinmeyen parametre olarak ele almış ve yeni bir PPP matematiksel modeli ifade etmiştir. Gerçek zamanlı olarak veri üreten 80 IGS istasyonu kullanılarak gerçekleştirilen kinematik çözümlerde, geleneksel PPP yöntemine kıyasla, PPP-AR yönteminin, elde edilen konum bileşenlerine \%58 $(4.8 \mathrm{~cm}-2.2 \mathrm{~cm})$, yakınsama süresinde ise $\% 32$ (31.6 dakika-21.4 dakika) oranında katkı sağladığı ifade edilmiştir. Ortaya koyulan yeni yaklaşımda ise, PPP-AR yönteminin konum bileşenlerindeki katkısı \%53(4.1 $\mathrm{cm}-2.2 \mathrm{~cm})^{\prime}$ olarak belirtilmiştir.

\subsection{Verilerin Toplanması ve Analiz}

Kinematik PPP yönteminin hidrografik yada oşinografik ortamlardaki performansını değerlendirmek için iki adet Topcon Hiper-Pro GNSS alıcısı kullanılmıştır. GNSS alıcılarından birisi bağıl konum belirleme çözümü için karaya, kıyıdan yaklaşık $100 \mathrm{~m}$ uzaklıktaki bir noktaya, sabit alıcı olarak kurulmuş, diğer GNSS alıcısı ise zodyak botunun üzerine bağlanılmıştır (Şekil 1, Şekil 2).

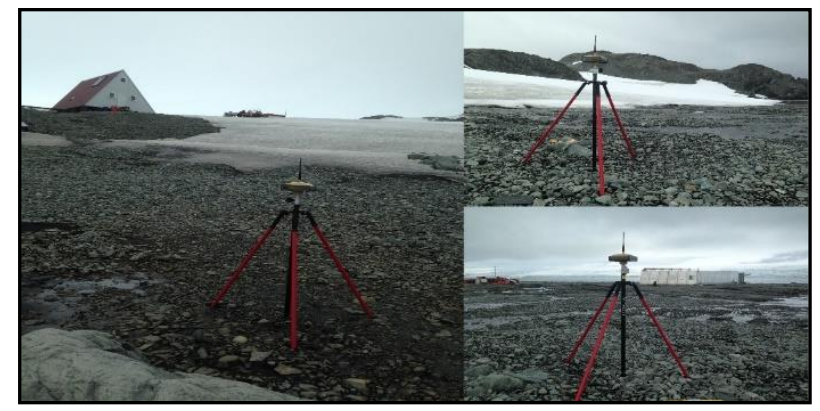

Şekil 1. Sabit GNSS AlıcıSı

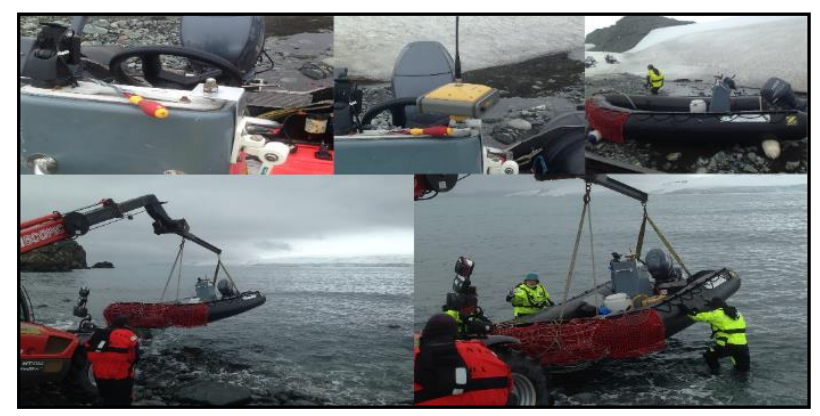

Şekil 2 Deneylerde Kullanılan Zodyak bot ve GNSS alıcıSı

Bu çalışma 18.02.20108 (test 1) ve 19.02.2018 (test 2) tarihlerinde Şekil 4' de belirtilen güzergahlar üzerinde gerçekleşmiştir. Test 1 için, Livingston adasında bulunan Bulgarian Antarctic Base' den yola çıkılmış, düz bir rotada yaklaşık $12 \mathrm{~km}$ uzaklıktaki Hannah Point isimli yere gidilmiştir. Burada Zodyak botu karaya bağlanılmış bir süre beklenilmiş, fakat gel-git etkisinden dolayı dolayı zodyak botu karaya oturmuştur. Suların tekrar yükselmesi için yaklaşık 4 saat karada beklenilmiştir (Şekil 3). Daha sonra yine Livingston adasında bulunan Spanish Antarctic Base' e gidilmiş ve üsse geri dönülmüştür. Deney başlatılmadan önce, yani botun hareket etmesine başlamadan önce, başlangıç tamsayı belirsizliğinin (ambiguity) yakınsaması yada çözülebilmesi için yaklaşık 25 dakika zodyak botu üzerinde hareketsiz bekletilmiştir. Deney sırasında elde edilen ve GPS ve 
GLONASS uydu kombinasyonları ile toplanan veriler CSRS-PPP servisinin eski (Geleneksel PPP) ve yeni (PPP-AR) versiyonu ile değerlendirilmiştir. Veriler $10^{\circ \prime}$ lik yükseklik açısında toplanırken, her iki günün PPP sonuçlarının doğruluğunu epok-epok analiz etmek için referans alınan, bağıl çözümler ise Leica Geo Office 3.0 programı kullanılarak GPS+GLONASS uydu kombinasyonları ile değerlendirilmiştir.

Test 2' de ise yine test 1 dekine benzer bir şekilde bir GNSS alıcısı karaya diğer bir GNSS alıcısı ise zodyak botuna bağlanılmıştır. Yine Livingston adasında bulunan Bulgarian Antarctic Base' den yola çıkılmış olup Pimpirev Glacier' leri arasında karışık bir rota izlenmiştir (Şekil-4). Test 1'de bahsedildiği gibi, elde edilen veriler CSRS-PPP servisinin eski ve yeni yazılımı ile değerlendirilmiştir. Değerlendirmede kullanılan bazı parametreler Çizelge $1^{\prime}$ de ifade edilmiştir

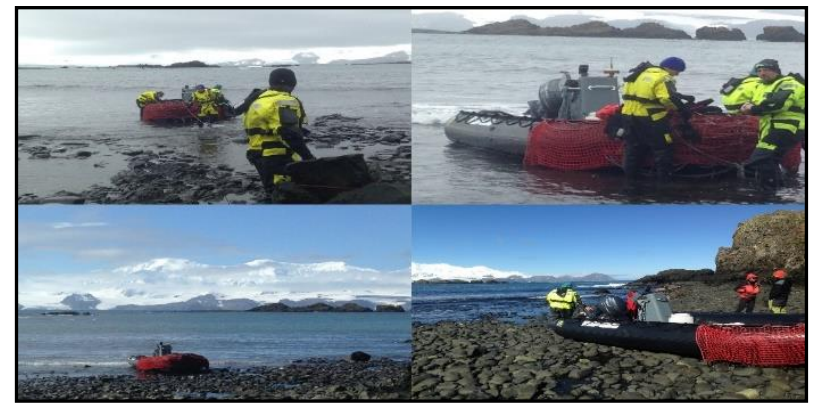

Şekil 3. Hannah Point ve karada beklenen zaman.

Çizelge 1. CSRS-PPP tarafından kullanılan işlem parametreleri.

\begin{tabular}{ll}
\hline Aylarlar & Parametre \\
\hline Mod & Kinematik \\
\hline Proses Edilen Gözlemler & Kod\&Faz \\
\hline Uydu Yörüngeleri & L3 \\
\hline Uydu Girdileri & Hassas \\
\hline İyonosferik Modeller & CLK-RINEX \\
\hline Marker Koordinatlaro & L1\&L2 \\
\hline Troposferik Zenit Gecikmesi (ZTD) & Tahmin \\
\hline Saat Enterpolasyonu & Edilmiş \\
\hline Parametre Yumuşatma & Tahmin \\
\hline Saat Enterpolasyonu & Edilmiş \\
\hline Referans Yüzeyi & Evet \\
\hline Enlem, Boylam ve h parametreleri için & WGS84 \\
Referans Alınan Elipsoid & ITRF \\
\hline Koordinat Sistemi & Elipsoidal \\
\hline Uydu Saat Aralığı (Sn.) & 30 \\
\hline Pseudorange Hatası (m) & 2.000 \\
\hline Taşıyıcı Faz Hatası (m) & 0.020 \\
\hline
\end{tabular}

\section{Bulgular}

Her iki test verilerinin CSRS-PPP eski ve yeni versiyonu kullanılarak elde edilen Geleneksel PPP ve PPP-AR koordinat bileşenlerinin epok-epok referans olarak kabul edilen bağıl çözümlerden farkları elde edilmiştir. Şekil-5 her iki test sonucu elde edilen koordinat bileşenleri farklarını göstermektedir. Ayrıca bu farkların; ortalaması ve standart sapması Çizelge-2' de her iki gün için karşılaştırılmalı olarak gösterilmiştir.

Çizelge 2. Kinematik PPP ve PPP-AR Sonuçlarının İstatiksel Analizi.

\begin{tabular}{llllll}
\hline \multirow{2}{*}{} & & \multicolumn{2}{c}{ Test 1 } & \multicolumn{2}{c}{ Test 2 } \\
\cline { 2 - 6 } & & PPP & PPP-AR & PPP & PPP-AR \\
\hline \multirow{2}{*}{ N (Kuzey) } & Ort. (cm) & 1.0 & 0.8 & -2.0 & -0.8 \\
\cline { 2 - 6 } & SD (cm) & $\mathbf{1 . 6}$ & $\mathbf{1 . 3}$ & $\mathbf{3 . 1}$ & $\mathbf{2 . 2}$ \\
\hline \multirow{2}{*}{ E (Doğu) } & Ort. (cm) & -0.3 & -0.1 & -3.0 & -1.3 \\
\cline { 2 - 6 } & SD (cm) & $\mathbf{1 . 5}$ & $\mathbf{0 . 9}$ & $\mathbf{3 . 6}$ & $\mathbf{2 . 3}$ \\
\hline \multirow{2}{*}{ h (Yükseklik) } & Ort. (cm) & 1.4 & 0.9 & -3.4 & -1.1 \\
\cline { 2 - 6 } & SD (cm) & $\mathbf{3 . 2}$ & $\mathbf{3 . 5}$ & $\mathbf{5 . 8}$ & $\mathbf{4 . 2}$ \\
\hline
\end{tabular}

Çizelge 2' de görüldüğü üzere Test 1 de PPP-AR ile elde edilen çözümlerin standart sapmaları (SD) Geleneksel PPP ile elde edilen standart sapmalardan $\mathrm{N}$ ve $\mathrm{E}$ bileşenleri için daha küçük olduğu, yükseklik bileşeninde biraz daha büyüktür. Fakat farkların ortalama değerleri PPP-AR yönteminde sıfıra daha iyi yakınsamıştır. Bu durum Şekil $6^{\prime}$ da verilen farkların histogramlarında da açıkça görülebilmektedir. Her üç bileşenin farklarının zaman serisi dikkate alındığında PPP-AR çözümlerinin daha stabil olduğu açıktır.

Test 2 sonuçları incelendiğinde PPP-AR çözümlerinin standart sapmalarının genellikle Geleneksel PPP yönteminden biraz daha küçük olduğu görülmektedir. Ayrıca, PPP-AR çözümlerinin hata ortalamalarının belirgin bir şekilde sıfıra daha yakın olduğu görülmektedir. Benzer şekilde bu durum Şekil 6 da verilen histogramlarda da açıkça fark edilmektedir.

Bölüm 2.1' de bahsedilen Test 1 sırasında Hannah Point adlı yere ulaşmak için katedilen mesafe yaklaşık olarak 12 km dir. Bağıl çözüm için, referans GNSS alıcısından uzaklaştıkça sinyalleri etkileyen hataların korelasyonları belirli miktarda azalacağı için konumsal hassasiyetinde azalması beklenir. Her ne kadar bu çalışmada referans alıcıyla gezen alıcı arasındaki mesafe en fazla $12 \mathrm{~km}$ ye ulaşsa da referans alıcıdan uzaklaştıkça hata miktarında bir değişim olup olmadığının analizi yapılmıştır. Şekil 7 
geleneksel PPP ve PPP-AR yönteminden olan farkları göstermektedir. Şekil 7'den de görüldüğü üzere referans alıcıdan uzaklaştıkça hata miktarlarının anlamlı bir değişime uğramadığı gözlenmektedir. Bu analizi gerçekleştirmenin temel sebebi bağıl yöntemin referans alıcıdan uzaklaştıkça konum belirleme duyarlığının azalıp azalmadığını ve PPP yöntemlerinin performanslarının değerlendirilmesi için referans olarak alınıp alınamayacağını test etmek amacıyla gerçekleştirilmiştir. PPP yöntemi herhangi bir referans alıcıya bağlı çözüm üretmediği için elde edilen konum doğruluğu ve hassasiyeti mesafeyle ilişkili değildir. Elde edilen bulgular, bu çalışma için bağıl yöntemin güvenilir bir şekilde referans olarak alınabileceğini işaret etmiştir.

Yine Bölüm 2.2' de bahsedilen "Hannah Point" isimli noktanın olduğu adada zodyak botunun karaya oturduğu anlardaki, yani GNSS alıcısının hareketsiz olduğu zamanlarda, toplanan GNSS verileri, Kinematik PPP yöntemlerinin tekrar edilebilirliklerini incelemek için bağıl çözümlerle karşılaştırımıştır. Geleneksel PPP ve PPP-AR yönteminin bağıl yöntemden olan Epok-epok farkları, farkların ortalaması ve standart sapmaları elde edilmiştir. Farkların histogramları, ortalama değerleri ve standart sapmaları Şekil 8'de verilmiştir. Görüldüğü üzere farkların dağılımı genelde gauss-hata eğirisine uymaktadır. PPP-AR çözümünden elde edilen farkların standart sapma değerleri $\mathrm{N}$ ve $\mathrm{E}$ bileşenleri için biraz daha küçük iken, $\mathrm{h}$ bileşeni biraz daha büyüktür. Her bir yöntemden elde edilen epok-epok koordinat değerlerinden ortalama koordinat değerleri ve standart sapmaları da hesaplanmış ve Çizelge $3^{\prime}$ de verilmiştir. Standart sapmalar incelendiğinde $\mathrm{N}$ ve $\mathrm{E}$ konum bileşenlerinin tekrar edilebilirliklerinin her üç yöntem içinde benzer olduğu, fakat bağıl yöntemin h-yükseklik bileşeninin tekrar edilebilirliğinin her iki PPP yöntemlerinden biraz daha iyi olduğu görülmektedir. Geleneksel PPP ve PPP-AR sonuçlarının birbirine daha yakın olduğu açıkça göze çarpmaktadır. Her üç yöntemde de Doğu $(E)$ bileşenin tekrar edilebilirliği hem Kuzey $(N)$ hem de yükseklik (h) bileşenin tekrar edilebilirliğinden daha kötü olduğu göze çarpmaktadır. Bunun sebebinin bölgenin Dünya üzerindeki konumu ve GNSS uydularının Kuzey-Güney yönünde hareket etmesinden dolayı kaynaklandığı düşünülmektedir.

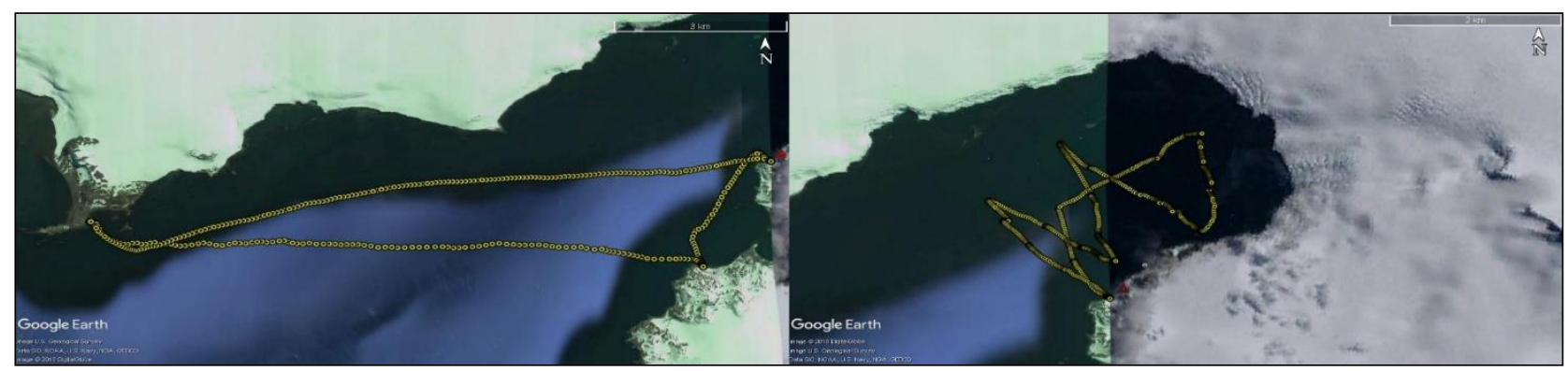

Şekil 4. Test 1 (Sol) ve Test 2 (Sağ) Güzergahları.

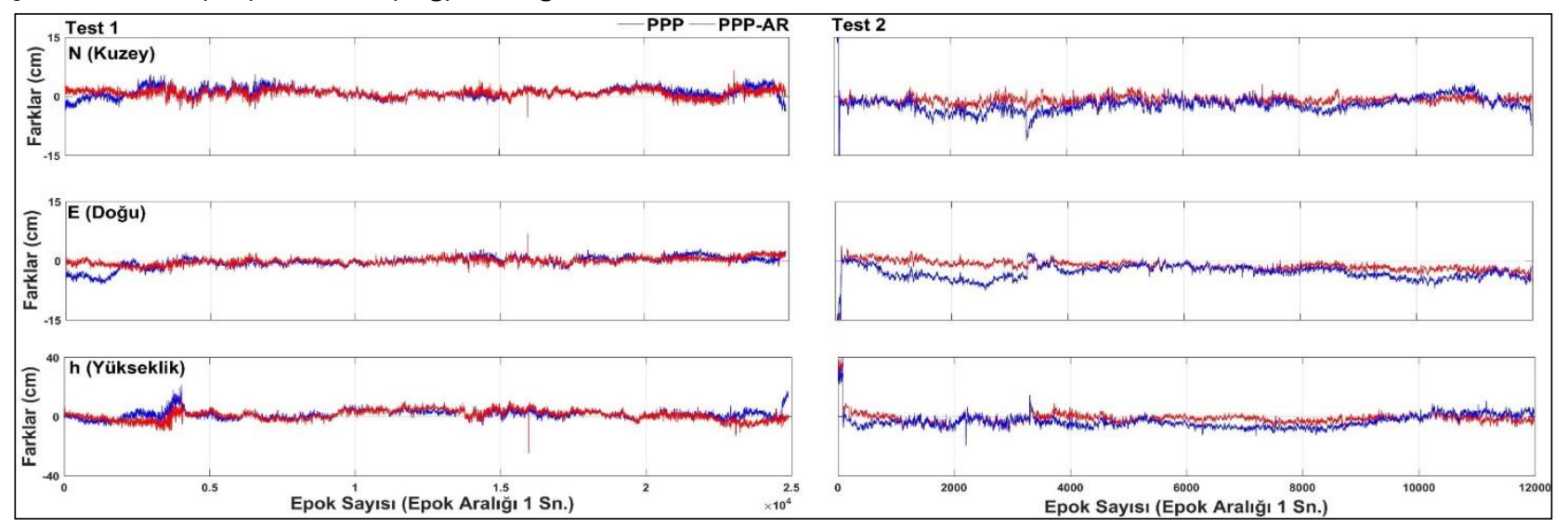

Şekil 5. PPP ve PPP-AR yöntemlerinin bağıl yöntemden olan farkları 


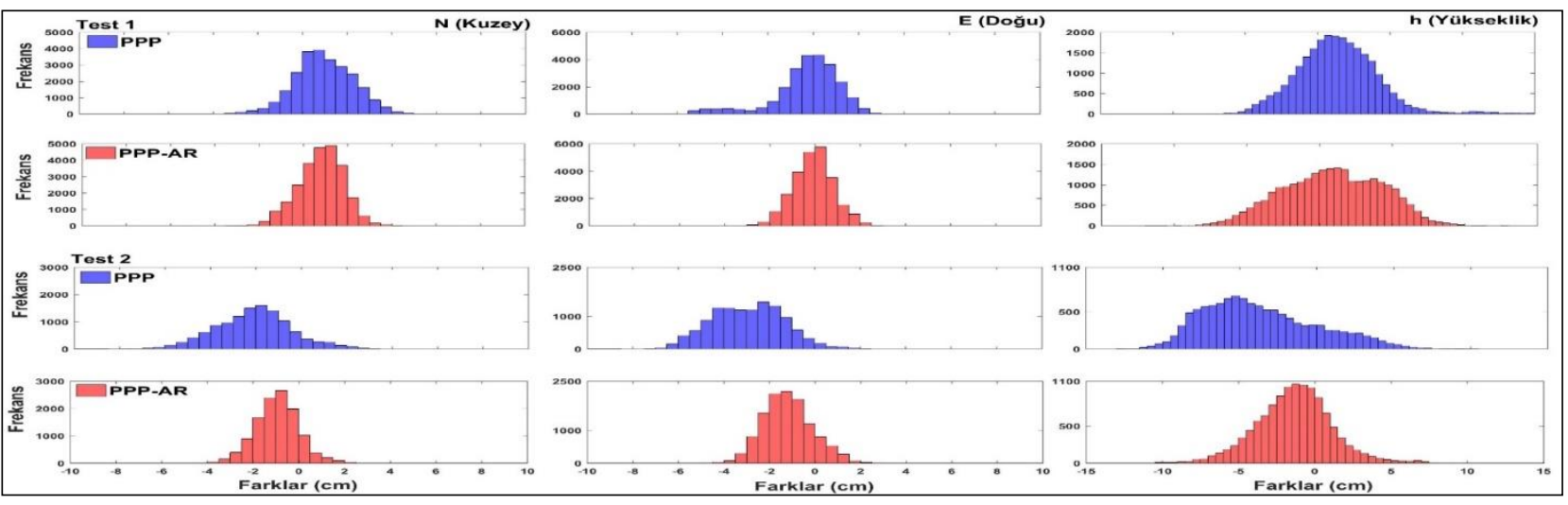

Şekil 6. PPP ve PPP-AR yöntemlerinin bağıl yöntemden olan farklarının histogtamları.

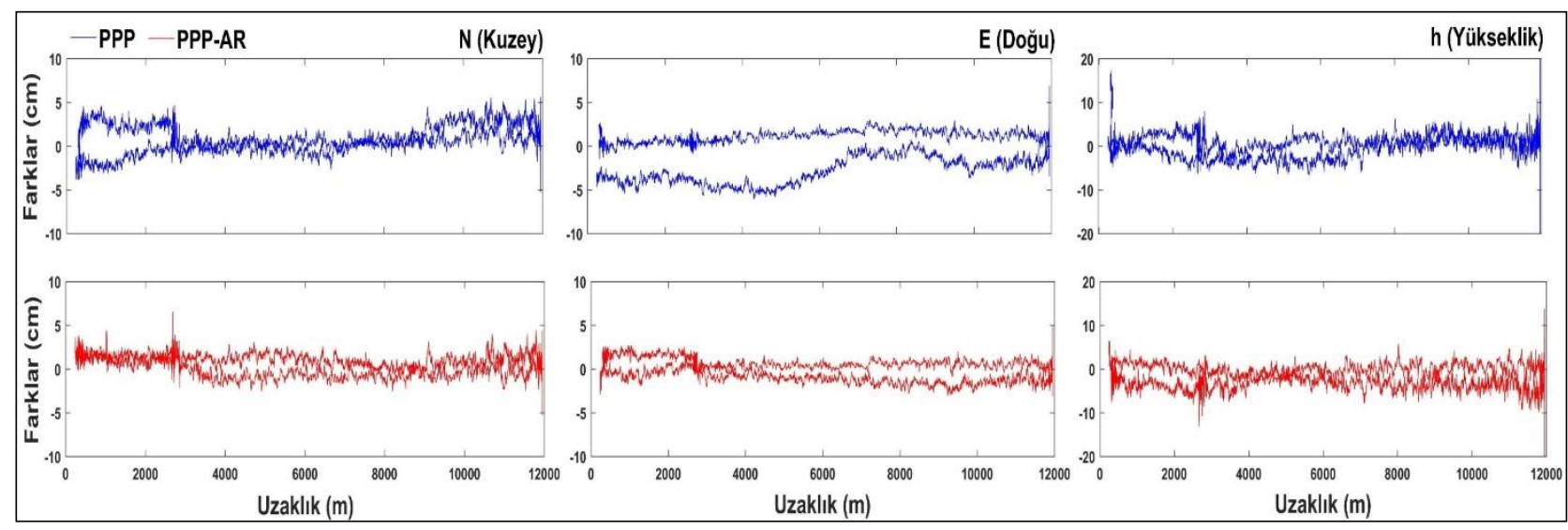

Şekil 7. PPP ve PPP-AR yöntemlerinin bağıl yöntemden olan farklarının referans noktadan olan uzaklığına göre değişimi

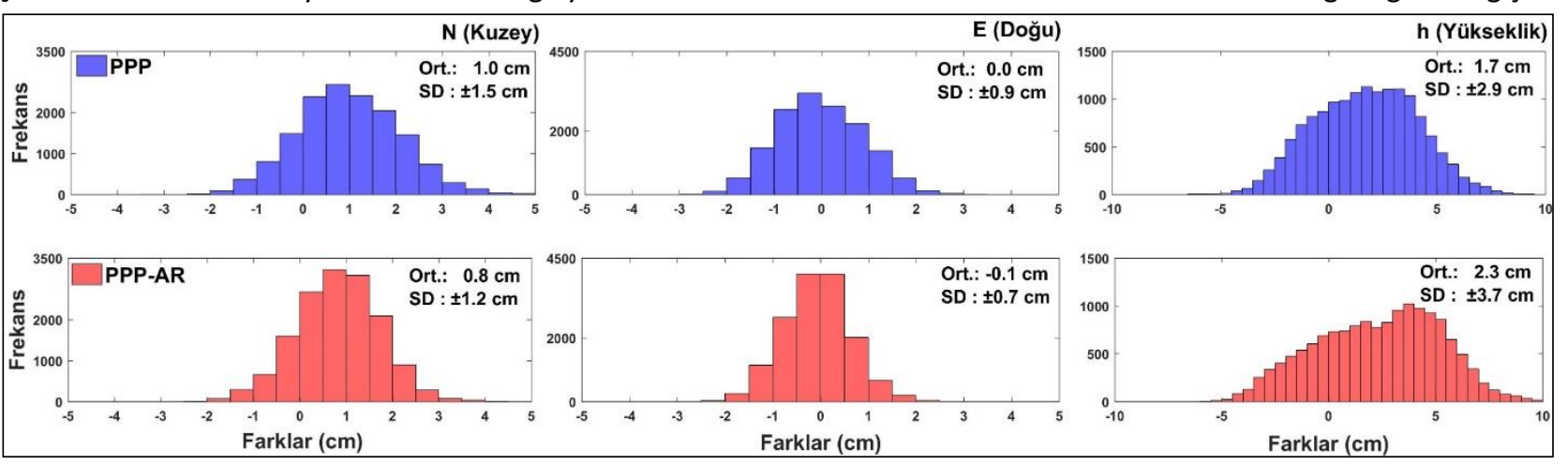

Şekil 8. Karada beklenen anlar için PPP ve PPP-AR yöntemlerinin bağıl yöntemden olan farklarının histogramları

Çizelge 3. Bağıl, PPP ve PPP-AR yöntemlerinden elde edilen ortalama koordinat değerleri ve standart sapmaları.

\begin{tabular}{lllll}
\hline & & Rölatif & PPP & PPP-AR \\
\hline \multirow{2}{*}{$\mathrm{N}$} & Ort. (m) & 3050831.242 & 3050831.232 & 3050831.234 \\
\cline { 2 - 5 } & SD (cm) & 1.1 & 1.2 & 1.2 \\
\hline \multirow{2}{*}{$\mathrm{E}$} & Ort. (m) & 623109.414 & 623109.415 & 623109.415 \\
\cline { 2 - 5 } & SD (cm) & 6.0 & 5.8 & 5.9 \\
\hline \multirow{2}{*}{$\mathrm{h}$} & Ort. (m) & 20.362 & 20.346 & 20.339 \\
\cline { 2 - 5 } & SD (cm) & 1.1 & 2.4 & 2.9 \\
\hline
\end{tabular}

\section{Tartışma ve Sonuç}

Bu çalışmada geleneksel PPP ve PPP-AR yönteminin hidrografik yada oşinografi uygulamalardaki performansını değerlendirmek için Antarktika Yarımadası'nda yer alan Livingston adası civarında bir dizi deney gerçekleştirilmiştir. GPS/GLONASS uydu kombinasyonları ile elde edilen veriler kinematik modda CSRS-PPP servisinin eski (Geleneksel PPP) ve yeni (PPP-AR) versiyonu ile değerlendirilmiştir.

Bulgularımız PPP-AR yönteminin geleneksel PPP yöntemine kıyasla daha duyarlı olduğunu 
göstermiştir. Sonuçlar, Alkan vd (2017)'de belirtildiği gibi hidrografik-oşinografik ölçmeler için Uluslararası Hidrografik Organizasyonu (International Hydrographic Organization-IHO) tarafından beklenen minimum konumsal doğruluk değerlerine ulaşıldığını göstermektedir. Genel olarak bu doğruluk seviyesinin, seyrüsefer, deniz mühendisliği, inşaat çalışmalar, kablo ve boru hattı döşeme, liman işleri, hassas hidrografik ölçüm, oşinografi, kıyı yönetimi gibi çalışmalar için yeterli olduğu görülmektedir. Ayrıca, CSRS-PPP servisi, gerçekleştirdiği modernizasyonu ile daha yüksek duyarlıklı kinematik çözüm elde etmeye ve rölatif yöntemin kullanılamadığı durumlarda alternatif çözümler üretmeye olanak sağlamıştır.

\section{Teşekkür}

"Bu çalışma T.C. Cumhurbaşkanlığı himayesinde, T.C. Bilim, Sanayi ve Teknoloji Bakanlığı uhdesinde ve iтÜ Kutup Araştırmaları Uyg-Ar Merkezi koordinasyonunca desteklenmiştir. İkinci yazar Curtin Universitesi (WA, Australia) 'nde doktora sonrası araştırmaları için destek veren TÜBITAK-BIDEB e teşekkür eder.

\section{Kaynaklar}

Alkan, R.M., Öcalan, T., 2013. Usability of the GPS Precise Point Positioning Technique in Marine Applications. The Journal Of Navigation, 66, 579-588.

Alkan, R.M., Saka, M. H., Ozulu, M. İ., İlçi, V., 2017. Kinematic precise point positioning using GPS and GLONASS measurements in marine environments. Measurement, 109(2017), 36-43.

Bisnath, S., Gao, Y., 2009. Precise point positioning, a powerful technique with a promising future,. GPS World, 20 (4), 44-50.

Chadwell, C.D., Spiess, F.N., 2008. Plate motion at the ridge-transform boundary of the south Cleft segment of the Juan de Fuca Ridge from GPS-Acoustic data. Journal of Geophysical Research, 113, B04415.

El-Mowafy, A., 2011. Analysis of web-based GNSS postprocessing services for static and kinematic positioning using short data spans. Survey Review, 43, 535-549
Geng, J., Teferle, F.N., Meng, X. and Dodson, A.H., 2010. Kinematic Precise Point Positioning at Remote Marine Platforms. GPS Solutions, 14 (4), 343-350.

Kato, T., Terada, Y., Ito, K., Hattori, R., Abe, T., Miyake, T., Koshimura, S., Nagai, T., 2005. Tsunami due to the 2004 September 5 th off the Kii peninsula earthquake, Japan, recorded by a new GPS buoy. Earth Planets Space, 57(4), 297-301.

Kouba, J., 2003. Measuring seismic waves induced by large earthquakes with GPS, Studia Geophysica et Geodaetica, 47 (4), 741-755.

Larson, K.M., Bodin, P., Gomberg, J., 2003. Using 1-Hz GPS data to measure deformations caused by the Denali Fault earthquake, Science, 300 (5624), 1421-1424.

Li, X., Ge, M., Zhang, H., Wickert, J., 2013. A method for improving uncalibrated phase delay estimation and ambiguity-fixing in real-time precise point positioning. Journal Of Geodesy, 87(5), 405-416

Marreiros, J., P., R., 2012. Kinematic GNSS Precise Point Positioning: Application to marine platforms. PhD Thesis, University Of Porto, Faculty of Sciences, Porto, 177.

Mireault, Y., Tétreault P, Lahaye F, Héroux P, Kouba J.., 2011. Online Precise Point Positioning: A New, Timely Service from Natural Resources Canada. GPS World, 19(9), 59-64

Watson, C.S.., 2005. Satellite altimeter calibration and validation using GPS buoy technology. PhD Thesis, University Of Tasmania, Centre for Information, Tasmania, 313.

Xu, P., Shi, C., Fang, R., Liu, J., Niu, X., Zhang, Q. Yanagidani, T., 2013. High-rate precise point positioning (PPP) to measure seismic wave motions: an experimental comparison of GPS PPP with inertial measurement unit,. Journal of Geodesy, 87 (4), 361372.

Yigit, C.O., 2016. Experimental assessment of postprocessed kinematic Precise Point Positioning method for structural health monitoring. Geomatics, Natural Hazards and Risk, 7(1), 360-383. 


\section{internet kaynakları}

1-https://webapp.geod.nrcan.gc.ca/geod/tools-

outils/documentation.php, (25.09.2018) 